\title{
Ingestion of carbohydrate-rich supplements during gestation programs insulin and leptin resistance but not body weight gain in adult rat offspring
}

\author{
Bernard Beck ${ }^{1}$, Sébastien Richy ${ }^{1}$, Zoe A. Archer ${ }^{2}$ and Julian G. Mercer ${ }^{2}$ \\ EA 3453, Systèmes Neuromodulateurs des Comportements Ingestifs, Génétique et Développement, Université Henri Poincaré, Nancy, France \\ ${ }^{2}$ Division of Obesity and Metabolic Health, Rowett Institute of Nutrition and Health, University of Aberdeen, Aberdeen, UK
}

\section{Edited by:}

Catalina Pico, University of the

Balearic Islands, Spain

\section{Reviewed by:}

Celine Fassot Lucht, Institut National de la Santé et de la Recherche Médicale, France

Marlon E. Cerf, South African Medical Research Council, South Africa

\section{${ }^{*}$ Correspondence:}

Bernard Beck, Institut National de la Santé et de la Recherche Médicale, France, U954, Faculté of Medicine 9 avenue de la Forêt de Haye, BP 184, 54500 Vandouvre, France.

e-mail: bernard.beck@inserm.fr
Prenatal nutritional conditions can predispose to development of obesity and metabolic syndrome in adulthood. Gestation with its important modifications in hormonal status is a period of changes in normal feeding habits with pulses of consumption or avoidance of certain categories of food. We tried to mimic in an animal model some changes in food consumption patterns observed in pregnant women. For this purpose, Long-Evans female rats were fed during the dark period, their usual pre-gestational food quantity, and were allowed to complete their daily intake with either a restricted control $(\mathrm{Cr})$, high-fat (HF), or high-carbohydrate $(\mathrm{HC})$ diet available ad libitum during the light period. Dams fed a control diet ad libitum (Ca) served as controls. Body weight and composition, food intake, and metabolic hormones (insulin, leptin) were recorded in male offspring until 20 weeks after birth. $\mathrm{Cr}$ and $\mathrm{HC}$ females ate less than $\mathrm{Ca}$ females $(-16 \% ; p<0.001)$ and their offspring presented a weight deficit from birth until 6 (HC group) and 10 (Cr group) weeks of age ( $p<0.05$ or less). Plasma leptin corresponded to low body weight in $\mathrm{Cr}$ offspring, but was increased in $\mathrm{HC}$ offspring that in addition, had increased plasma insulin, blood glucose, and subcutaneous adipose tissue mass. HF dams ate more than $\mathrm{Ca}$ dams $(+13 \% ; p<0.001)$, but plasma leptin and insulin were similar in their offspring. Hypothalamic Ob-Rb expression was increased in $\mathrm{Cr}, \mathrm{HC}$, and HF offspring (+33-100\% vs Ca; $p<0.05$ or less). HC supplement ingestion during gestation therefore leads to insulin and leptin resistance in adult offspring independently of lower birth weight. These hormonal changes characterize obesity-prone animals. We therefore suggest that attention should be paid to the carbohydrate snacking and overall carbohydrate content in the diet during the last weeks (or months) preceding delivery to limit development of later metabolic disorders in offspring.

Keywords: fetal programming, high-fat, dietary preference, adipose tissue distribution, hypothalamic Ob-Rb expression, ghrelin

\section{INTRODUCTION}

Gestation and early postnatal life are periods of development during which sensitivity and susceptibility to environmental factors are considerable (Cottrell and Ozanne, 2008). This has led to the concept of fetal programming initiated by Barker more than 20 years ago for cardio-vascular diseases (Godfrey and Barker, 2000). According to this hypothesis, these early external factors can alter the genome through epigenetic changes (methylation or acetylation), that render people susceptible to develop metabolic diseases later in life. Feeding conditions likely constitute one of the most influential parameters for the future of the young in terms of health and psychological well-being. During these early periods of development, food supply both in terms of quantity and quality is totally outside the control of the offspring and depends completely on the mother's dietary and nutritional habits. It is also well-known that pregnancy triggers changes in feeding habits, firstly in relation to the substantial hormonal changes induced during this state, and second because of the increasing energy needs of the developing embryo from the conception until birth (Butte et al., 1999, 2004). Food preferences vary across the course of pregnancy (Bowen, 1992). Food cravings and aversions are reported by a sizable proportion of pregnant women (Dickens and Trethowan, 1971; Hook, 1978; Pope et al., 1992). This could lead to rather important changes in dietary intake both for macro- and micronutrients. Indeed, food cravings are mainly focused on sweet carbohydrate-rich food items (candy, chocolate, pies, fruit juices...) although some of these also contain a significant proportion of fats. The consequences for offspring development and metabolism of these unbalanced diets enriched in fats or carbohydrates and ingested by the mother have been studied in some detail (Kozak et al., 1998, 2000; Wu et al., 1998; Buckley et al., 2005; Srinivasan et al., 2006). Both behavioral and hormonal changes have been detected in offspring following the ingestion of such diets. The development of dietary preferences across the whole life-time is affected by the maternal diet both in rats and in humans (Marlin, 1983; Kozak et al., 2005; Bayol et al., 2007; Chang et al., 2008; Nakashima, 2008; Brion et al., 2010). The main hormonal changes in the offspring were observed 
for two important metabolic peptides, insulin and leptin, with the development of resistance or insensitivity in offspring born to dams fed high-fat (HF) diets (Bispham et al., 2003; Dyrskog et al., 2005; Srinivasan et al., 2006; Cerf et al., 2009). However, all these results come from experiments where only one diet was fed, and where feeding was given ad libitum and imposed during the whole of the gestation and/or suckling periods without any choice. Such manipulations do not reflect the situation that is generally observed during human pregnancy where food is usually taken as three meals, generally of balanced composition with additional ingestion of unbalanced supplements (snacks) in-between these meal time periods. This forms the rationale for the development of an animal model that attempts to mimic, as accurately as possible, human behavior. We fed pregnant female rats two fixed quantities of a balanced diet provided close to the light/dark transitions when rat intake is normally high, and gave them the option of an additional voluntary ad libitum feed of either a HF diet or a high-carbohydrate (HC) diet during the light period when feeding would normally be low or absent. We speculate that meal intake may contribute to the maintenance of weight gain within an appropriate range, whereas the ingestion of the unbalanced supplement could contribute to overeating and/or junk eating. In this model, we measured body weight changes in dams and pups and investigated the consequences of these feeding conditions for dietary preferences, and circulating leptin and insulin levels in offspring from weaning until adulthood. The dietary treatment was imposed on the dams during the second part of the gestation because this period is a period of rapid fetal development, but it is also associated with gestational diabetes and/or insulin resistance (Leturque et al., 1980; Moses et al., 1997).

\section{MATERIALS AND METHODS}

The experiment was conducted in accordance with the European Community Council Directive of November 24, 1986 $(86 / 609 / \mathrm{EEC})$ for the use and care of animals in research.

\section{ANIMALS AND PROTOCOL}

Female Long-Evans rats $(n=46)$ were purchased from Centre d'Elevage R. Janvier (CERJ; Le Genest St Isle, France). They were placed in individual Plexiglas cages with wood shavings in an airconditioned vivarium with a $12 \mathrm{~h}$ light- $12 \mathrm{~h}$ dark cycle. They were fed a control well-balanced breeding diet ad libitum for 2 weeks (see Table 1 for exact composition). Diet was given in a stainless steel cup placed on a small elevated platform in the cage to avoid contamination with wood shavings. Tap water was available ad libitum throughout the study except during the preference tests.

The time course of the protocol is shown in Figure 1. During the 2 weeks of habituation, the rats were handled daily, weighed, and their daily food intake (Q) was recorded during the second week. Measurement of cup weight at each light/dark transition indicated that the rats typically ingested two-thirds of their daily intake during the dark period. At the end of habituation period, the females were separated into four groups of body weight-matched animals and were mated with male Long-Evans rats obtained from the same provider and habituated to the vivarium conditions. The presence of vaginal plugs was checked and taken to be day 1 of pregnancy. During the first part of gestation (day 1 until day 12 of
Table 1 | Composition of the control, high-carbohydrate (HC), and high-fat (HF) diets given to the dams during gestation.

\begin{tabular}{llll}
\hline & Control & HC & HF \\
\hline INGREDIENT (g/kg) & & & \\
Carbohydrates $^{1}$ & 560 & 663 & 188 \\
Fats $^{2}$ & 120 & 55 & 437 \\
Casein $_{\text {Salts* }}^{*}$ & 230 & 192 & 285 \\
Vitamins* $^{*}$ & 40 & 40 & 40 \\
Cellulose & 10 & 10 & 10 \\
ENERGY (\%) & 20 & 20 & 20 \\
Carbohydrate & & & \\
Fat & 54 & 69.1 & 13.1 \\
Protein & 26 & 12.9 & 68.9 \\
Energy density & 20 & 18 & 18 \\
& 4.15 & 3.84 & 5.71 \\
\hline
\end{tabular}

All diets are supplemented with $0.2 \%$ methionine. ${ }^{1} 2 / 3$ corn starch and $1 / 3$ sucrose; ${ }^{2} 1 / 3$ oil and 2/3 margarine; *Salt mixture (UAR 205b; SAFE, Villemoisson sur Orge, France); **Vitamin mixture (UAR200b).

pregnancy), all females were fed the control breeding diet ad libitum. During the second part of gestation (day 12 of pregnancy until parturition), food availability of three groups was modified. During each of the first and last hours of the dark period, the females of these three groups received a meal corresponding to one-third of Q. This corresponded to consumption, during the dark period, of the same food quantity that the rats had been accustomed to eating during the equivalent period prior to being mated. During the light period, they were allowed to eat ad libitum either the control breeding diet [control restricted $(\mathrm{Cr})$ group; $n=15$ ], a HF diet (HF group; $n=10$ ), or a HC diet (HC group; $n=10$ ) for $6 \mathrm{~h}$ starting $3 \mathrm{~h}$ after lights-on in order to fulfill their daily intake. The fourth group (control ad libitum (Ca) group; $n=11$ ) continued to be fed the control breeding diet ad libitum during the entire light and dark periods. The exact composition of the three diets is indicated in Table 1. The three diets were supplemented with $0.2 \%$ methionine. Carbohydrate content was a mixture of complex (two-third) and simple (one-third) carbohydrates. Fat content was a mixture of different oils and margarine that provided a complete spectrum of fatty acids. The HF diet has been shown to influence plasma leptin as well as body composition or glucose metabolism in rats (Beck et al., 1994; Stricker-Krongrad et al., 1998).

Litter size was adjusted to $8-10$ pups 3 days after parturition in order to avoid any litter size effect on growth of offspring. From birth of the pups, females were fed ad libitum on the control diet until weaning at 21 days after birth.

At weaning, male pups were placed in individual wire cages in the same vivarium as their mother. During the period of rapid growth (first month post-weaning), they were fed the control breeding diet (20\% of protein), and then a balanced maintenance diet ( $18 \%$ of protein) until 20 weeks of age.

\section{MEASUREMENTS}

During pregnancy, food intake of the HF, HC, and Cr females during the light period was recorded daily. Food intake of the Ca group 


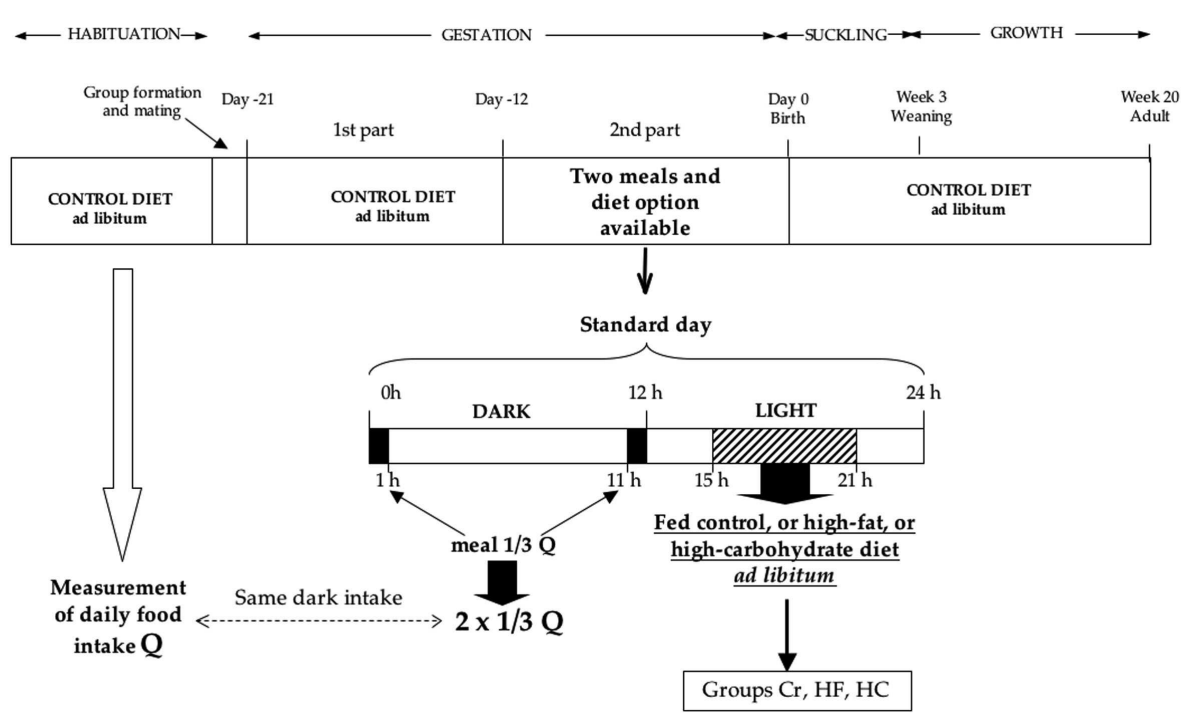

FIGURE 1 | Schematic representation of the experimental protocol.

was recorded daily. Intake of control diet of the four groups was recorded twice weekly during the suckling period. Body weight of females was measured at D0, D12, and D21 of gestation as well as at the weaning of their pups on postnatal day (PND) 21. Pup weight was recorded at PNDs 5, 12, and 21 (Ca group $n=76, \mathrm{Cr}$ group $n=80$, HF group $n=67$, and HC group $n=83$ ).

Pups were weighed at postnatal (PN) weeks 6 (around puberty), 10 (young adult), and 20 (mature adult). At PN week 12, their dietary preferences were tested through a two-bottle choice test.

\section{Dietary preferences}

Dietary preferences were measured in 12 week old rats from each of the four groups according to a modification of a previously described method (Kozak et al., 2005). The rats were given a choice between two bottles containing solutions rich either in fat (HFS) or carbohydrate (HCS). Solutions were isocaloric and contained an emulsifier and a thickener for a better stability of the mixture. Detailed composition is given in Table 2. The solutions were offered in random order and placed in the cage for $1 \mathrm{~h}$ during three consecutive days in the middle of the light period in order to habituate the animals to the procedure. On the fourth day, the rat had the choice between the two solutions for $1 \mathrm{~h}$ starting $3 \mathrm{~h}$ after lights-on. During these $3 \mathrm{~h}$, the rats had access to neither their regular diet nor water. Small cups were placed under the spouts of the bottles in order to recover any spillage. The same test was performed during the first hour of the dark period on the fifth day without prior food or water deprivation. Intakes of each solution were corrected for spillage (if any). The water bottle was withdrawn during each $1 \mathrm{~h}$ preference test.

\section{BLOOD AND ORGANS SAMPLING}

At the end of the suckling period (PND 21), randomly chosen pups from each group were killed by decapitation after light anesthesia $3 \mathrm{~h}$ after the beginning of the light period. Food but not water was withdrawn during this $3 \mathrm{~h}$ period in order that all animals would
Table 2 | Composition of the high-fat (HFS) and high-carbohydrate (HCS) solutions used for the determination of dietary preferences through the two-bottle choice test.

\begin{tabular}{|c|c|c|}
\hline Ingredient $(\mathrm{g} / 100 \mathrm{~mL})$ & HCS & HFS \\
\hline Skimmed milk & 8 & 8 \\
\hline Sucrose & 40 & - \\
\hline Oil $^{1}$ & - & 17.8 \\
\hline Glycerol monostearate ${ }^{2}$ & 1.3 & 1.3 \\
\hline Xanthan gum ${ }^{3}$ & 0.3 & 0.3 \\
\hline Water (QSF) & & \\
\hline
\end{tabular}

${ }^{1}$ ISIO4 (Lesieur - Neuilly sur-Seine, France); ${ }^{2}$ E 471 (Ets François - St Maur, France); ${ }^{3}$ Rhodygel (Rhone-Poulenc Group - Melle, France).

be in the same nutritional state. The remaining rats (Ca group $n=26$, Cr group $n=28$, HF group $n=31$, and HC group $n=26$ ) were killed at the end of the experiment (PN week 20), according to the same procedure.

Trunk blood was sampled in chilled test-tubes containing aprotinin $(5000 \mathrm{IU} / \mathrm{mL}$, Iniprol, Laboratoires Choay, Paris) and EDTA $(1.2 \mathrm{mg} / \mathrm{mL}$, Merck, Darmstadt). The tubes were centrifuged at $4^{\circ} \mathrm{C}$ for $30 \mathrm{~min}$. Plasma was then aliquoted and stored at $-20^{\circ} \mathrm{C}$ until assay. The brain was rapidly removed and immediately frozen at $-80^{\circ} \mathrm{C}$ for further analysis. Different fat depots (subcutaneous, epididymal, and perirenal) were also sampled and weighed.

\section{ASSAYS}

\section{Hormones and plasma parameter determination}

Plasma glucose, cholesterol, and triglycerides were measured by kits using enzymatic methods (BioMérieux, Marcy l'Etoile, France). Hormone levels were measured in duplicate by specific radioimmunoassays using commercially available kits: insulin antibody coated tubes for immunoreactive insulin (IRI) measurements (Insulin-CT; Cis bio International, Saclay, France) with rat 
insulin as standard (NOVO, Copenhagen, Denmark), a rat ghrelin kit (RK-031-31; Phoenix Europe GmbH, Karlsruhe, Germany), and a rat leptin kit (RL-83 K; Linco, St Charles, USA). Plasma samples were diluted for the ghrelin assay. All the samples were run in one assay for each hormone or plasma parameter analysis. An insulin sensitivity index (ISI) was calculated as plasma insulin $(\mathrm{ng} / \mathrm{mL})$ divided by plasma glucose $(\mathrm{mmol} / \mathrm{L})$.

\section{Leptin receptor mRNA expression}

Gene expression for the long form of the leptin receptor (Ob-Rb) was measured in the brain using in situ hybridization. The protocol used has been previously published (Mercer et al., 1996). Briefly, coronal cryostat sections $(20 \mu \mathrm{m})$ of hypothalamic brain tissue were cut from eight brains in each group. Hypothalamic sections were collected onto slides, with adjacent sections on consecutively numbered slides. This permitted $\mathrm{Ob}-\mathrm{Rb} \mathrm{mRNA}$ to be localized and quantified in the arcuate nucleus (ARC) of the hypothalamus. Slides were fixed, acetylated, and hybridized overnight at $58^{\circ} \mathrm{C}$ using $\left[{ }^{35} \mathrm{~S}\right]$-labeled cRNA probes $\left(1-2 \times 10^{7} \mathrm{cpm} / \mathrm{mL}\right)$. Autoradiographic images (Hyperfilm $\beta$-max; Amersham) were quantified using the Image-Pro Plus system. Data were manipulated using a standard curve generated from ${ }^{14} \mathrm{C}$ autoradiographic micro-scales (Amersham), and the integrated intensity of the hybridization signal computed. Results are given as a percentage of the control ad libitum fed group (Ca).

\section{STATISTICS}

Results are given as the mean \pm SEM. They were compared through variance analysis followed by a post hoc PLSD Fisher test or Kruskal-Wallis test followed by a Mann-Whitney test when necessary. A probability of less than 0.05 was considered statistically significant.

\section{RESULTS BODY WEIGHT AND FOOD INTAKE VARIATIONS Dams}

The changes in energy intake and body weight in dams during gestation are shown in Figure 2. Before gestation and during the first part of gestation, there was no difference in energy intake between the four groups. During the second part of gestation, there was a significant effect of diet type $(p<0.001)$. HF dams ingested 13\% more energy than the Ca dams $(p<0.001), 35 \%$ more than $\mathrm{Cr}$ dams $(p<0.001)$, and $32 \%$ more than HC dams $(p<0.001$; Figure 2A). Cr and HC dams ingested about $16 \%$ less than Ca dams $(p<0.001)$. Whereas the increase in energy intake during gestation vs before gestation amounted to 43 and $63 \%$ in $\mathrm{Ca}$ and HF dams, respectively, it was only about $20 \%$ in $\mathrm{Cr}$ and HC dams (Figure 2B).

During the first part of gestation, body weight gain was not significantly different between groups (about 13-14\%; $p=0.93$ ).Body weight gain was significantly lower in $\mathrm{Cr}$ and $\mathrm{HC}$ dams than in $\mathrm{Ca}$ and HF dams during the second part of gestation and during the whole gestation period ( $p<0.05$ or less; Figure 2C).

\section{Offspring}

Litter size was not significantly different between groups (median 10-11 pups/litter). Growth of the animals from a few days after birth (PND 5) until 20 weeks of age is shown in Figure 3. At PND 5, Cr and HC pups presented a body weight deficit when compared with $\mathrm{Ca}$ and $\mathrm{HF}$ pups ( $p<0.05$ or less). This deficit (5$7 \%$ ) was observed during the whole suckling period (Figure 3A), and persisted after weaning until 6 weeks of age for both groups $(p<0.05$ or less). At 10 weeks of age, only $\mathrm{Cr}$ rats weighed less than the three other groups ( $p<0.05$ or less). There were no body

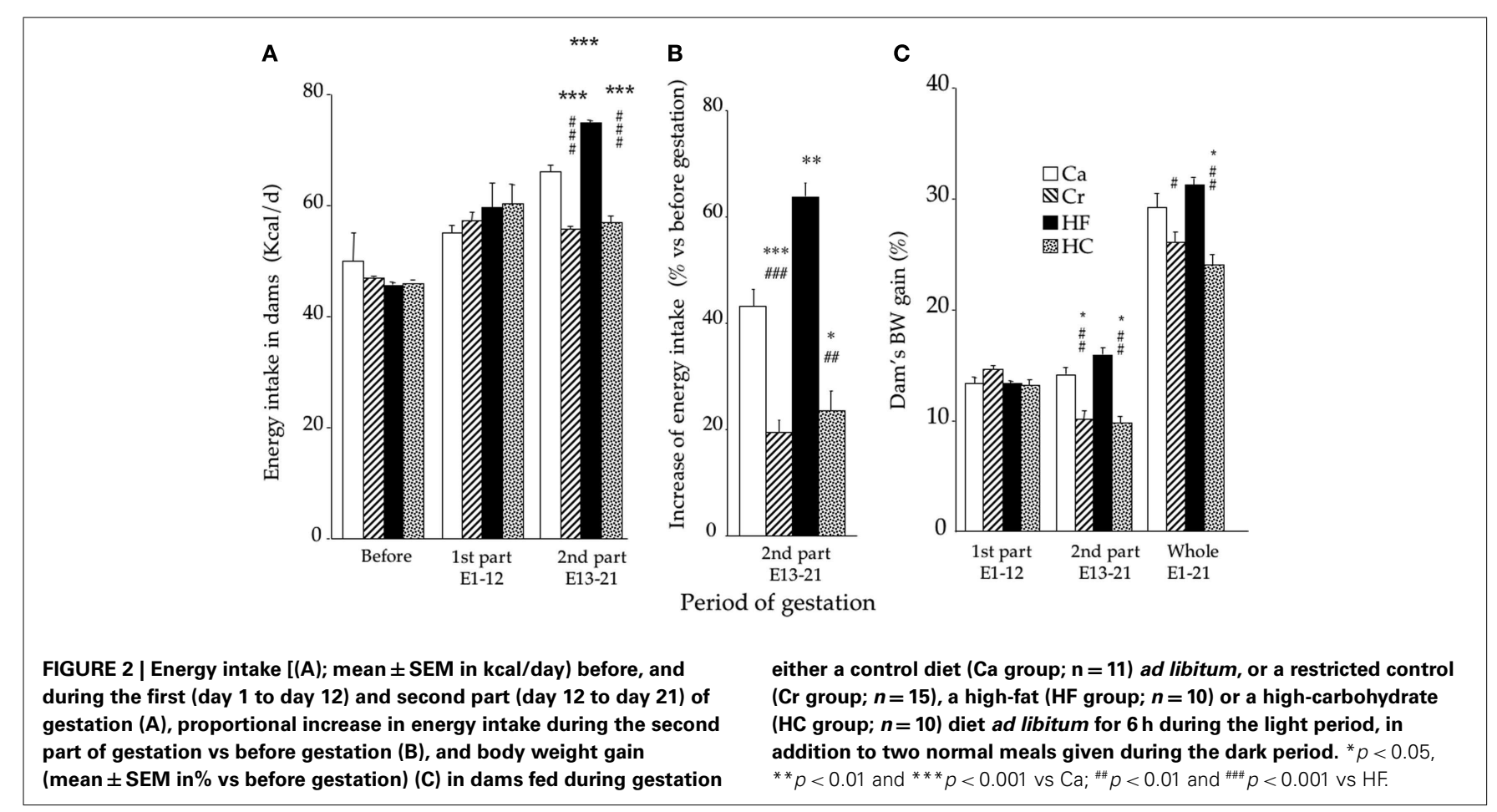


weight differences at 20 weeks of age (Figure 3B). However, at this age, there was a significant effect of maternal dietary treatment on adipose tissue distribution: $\mathrm{HC}$ rats had significantly more subcutaneous adipose tissue than $\mathrm{Cr}(p<0.01)$, and HF rats $(p<0.03)$, although weight of perirenal and epididymal fat depots did not vary between groups (Table 3 ).

After weaning, energy intake was only different at 6 weeks of age in $\mathrm{Cr}$ rats where it was significantly reduced by about $7 \%$ compared to $\mathrm{Ca}(p<0.01)$ and $\mathrm{HF}$ rats $(p<0.05)$ with no differences at weeks 10 and 20 (Table 4).

\section{DIETARY PREFERENCE TEST}

Ingestion of the HF and HC solutions during the two-bottle tests performed during either the light or the dark period at 12 weeks of age is shown in Figure 4. During the light period (Figure 4A), all rats preferred the HC solution $(p<0.001)$ but there were no

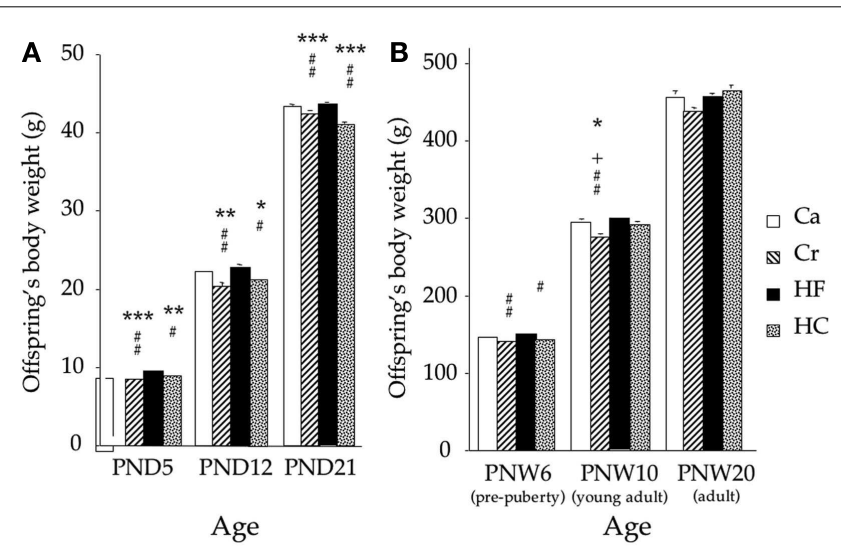

FIGURE 3 | Postnatal (PN) body weight (mean \pm SEM in grams) at different times of the suckling period [PN days 1-21; (A)] and after weaning (B) at PN weeks 6, 10, and 20 in offspring from dams fed during gestation either a control diet (Ca group) ad libitum, or a restricted control (Cr group), a high-fat (HF group) or a

high-carbohydrate (HC group) diet ad libitum for $6 \mathrm{~h}$ during the light period, in addition to two normal meals given during the dark period. ${ }^{*} p<0.05,{ }^{*} p<0.01$, and ${ }^{*}{ }^{*} p<0.001$ vs Ca; ${ }^{\#} p<0.05$ and ${ }^{\# \#} p<0.01$ vs $\mathrm{HF} ;{ }^{+} p<0.05$ vs HC.

Table 3 | Subcutaneous, perirenal, and epididymal fat depot weights (mean \pm SEM in grams) in offspring from dams fed either a gestational control diet (Ca group) ad libitum, or a restricted control (Cr group), a high-fat (HF group), or a high-carbohydrate (HC group) diet ad libitum for $\mathbf{6} \mathrm{h}$ during the light period, in addition to two normal meals given during the dark period.

\begin{tabular}{lcccc}
\hline Fat depot & \multicolumn{4}{c}{ Group of rats } \\
\cline { 2 - 5 } & Ca & Cr & HF & HC \\
\hline Subcutaneous & $19.8 \pm 1.0$ & $17.4 \pm 1.0$ & $18.4 \pm 0.8$ & $21.7 \pm 1.3^{\S \S \#}$ \\
Perirenal & $11.5 \pm 0.4$ & $10.6 \pm 0.4$ & $11.7 \pm 0.4$ & $11.4 \pm 0.3$ \\
Epididymal & $9.9 \pm 0.3$ & $9.7 \pm 0.3$ & $9.7 \pm 0.3$ & $10.2 \pm 0.3$ \\
Total & $41.2 \pm 1.7$ & $37.7 \pm 1.6$ & $39.8 \pm 1.4$ & $43.3 \pm 1.8$ \\
\hline
\end{tabular}

${ }^{s s} p<0.01$ vs $C r ; " p<0.03$ vs HF. differences between the four groups. HCS intake represented about $58-59 \%$ of the total intake measured during the $1 \mathrm{~h}$ test.

A similar preference for the HC solution was also noted during the dark period ( $p<0.001$; Figure 4B) but $\mathrm{Cr}$ rats ingested significantly more of the HF solution than the three other groups ( $p<0.05$ or less) during this nocturnal test. This led to a significantly higher total intake in $\mathrm{Cr}$ rats than in the three other groups $(p<0.05$ or less; Figure 4B).

\section{PLASMA PARAMETERS VARIATIONS IN OFFSPRING}

Plasma concentrations of glucose, triglycerides, cholesterol, and hormones are shown in Table 5. At weaning, there was no difference between the four groups for any parameter. At the end of the experiment ( 20 weeks of age), HC rats presented a basal hyperglycemia when compared with Ca rats ( $p<0.01$; Table 5), and their insulin concentration was significantly higher than that in $\mathrm{Ca}(p<0.05), \mathrm{Cr}(p<0.05)$, and HF $(p<0.001)$ rats (Table 5). The calculated ISI was significantly higher in $\mathrm{HC}$ rats than in $\mathrm{HF}$ rats $(2.04 \pm 0.15$ vs $1.46 \pm 0.09 ; p<0.005)$. It was also higher in $\mathrm{Ca}$

Table 4 | Post-weaning energy intake (mean \pm SEM in kcal/day) in offspring from dams fed either a gestational control diet (Ca group) ad libitum, or a restricted control (Cr group), a high-fat (HF group), or a high-carbohydrate (HC group) diet ad libitum for $\mathbf{6}$ h during the light period, in addition to two normal meals given during the dark period.

\begin{tabular}{lllll}
\hline Age & \multicolumn{5}{c}{ Group of rats } \\
& \multicolumn{5}{c}{ Ca } & Cr & HF & HC \\
\cline { 2 - 5 } & & & & \\
\hline Postnatal week 6 & $62.9 \pm 1.4$ & $57.9 \pm 1.2^{* *} \#$ & $62.4 \pm 1.2$ & $61.2 \pm 1.1$ \\
Postnatal week 10 & $68.6 \pm 1.4$ & $69.5 \pm 1.0$ & $66.5 \pm 1.2$ & $69.9 \pm 1.5$ \\
Postnatal week 20 & $72.0 \pm 1.3$ & $72.1 \pm 1.3$ & $70.4 \pm 1.3$ & $71.0 \pm 1.4$ \\
\hline
\end{tabular}

${ }^{*} p<0.01$ vs Ca; ${ }^{*} p<0.05$ vs HF.
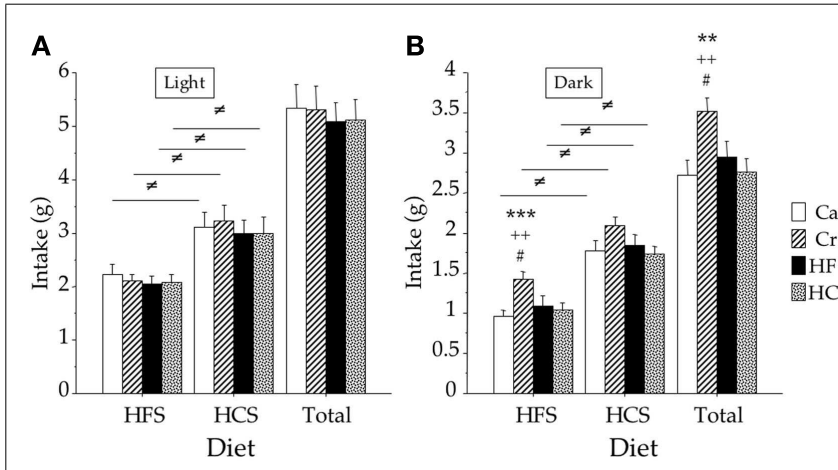

FIGURE 4 | Intakes (mean \pm SEM in grams) of high-fat (HFS) and high-carbohydrate (HCS) isocaloric solutions during dietary preference tests performed during light $(A)$ and dark $(B)$ periods in offspring from dams fed during gestation either a control diet (Ca group) ad libitum, or a restricted control (Cr group), a high-fat (HF group) or a high-carbohydrate (HC group) diet ad libitum for $6 \mathrm{~h}$ during the light period, in addition to two normal meals given during the dark period. ${ }^{\neq} p<0.001$ between HF and HC intakes for the same group; ${ }^{*} p<0.01$, and ${ }^{* *} p<0.001$ vs Ca; ${ }^{*} p<0.05$ vs HF; ${ }^{++} p<0.01$ vs HC. 
Table 5 | Blood glucose and plasma concentrations of triglycerides, cholesterol, immunoreactive insulin, and ghrelin (mean \pm SEM) in offspring from dams fed either a gestational control diet (Ca group) ad libitum, or a restricted control (Cr group), a high-fat (HF group), or a high-carbohydrate (HC group) diet ad libitum for $\mathbf{6}$ h during the light period, in addition to two normal meals given during the dark period.

$\begin{array}{llll}\mathrm{Ca} & \mathrm{Cr} & \mathrm{HF} & \mathrm{HC}\end{array}$

\begin{tabular}{|c|c|c|c|c|}
\hline \multicolumn{5}{|l|}{ WEANING } \\
\hline Blood glucose (mmol/L) & $7.8 \pm 0.1$ & $7.8 \pm 0.3$ & $7.6 \pm 0.4$ & $7.7 \pm 0.5$ \\
\hline Triglycerides (mmol/L) & $1.2 \pm 0.1$ & $1.3 \pm 0.2$ & $1.1 \pm 0.1$ & $1.5 \pm 0.3$ \\
\hline Cholesterol (mmol/L) & $3.0 \pm 0.3$ & $3.1 \pm 0.2$ & $2.9 \pm 0.1$ & $3.1 \pm 0.2$ \\
\hline Insulin (ng/mL) & $3.1 \pm 0.3$ & $4.0 \pm 0.4$ & $3.2 \pm 0.5$ & $2.8 \pm 0.6$ \\
\hline \multicolumn{5}{|l|}{ POSTNATAL WEEK 20} \\
\hline Blood glucose (mmol/L) & $8.3 \pm 0.3$ & $9.1 \pm 0.3$ & $8.9 \pm 0.2$ & $9.6 \pm 0.3^{* *}$ \\
\hline Insulin (ng/mL) & $15.1 \pm 1.4$ & $15.5 \pm 1.1$ & $12.8 \pm 0.8$ & $19.8 \pm 1.7^{*}$ §\#\#\# \\
\hline Ghrelin (pg/mL) & $810 \pm 58$ & $667 \pm 50$ & $761 \pm 51$ & $681 \pm 49$ \\
\hline
\end{tabular}

${ }^{*} p<0.05$ and ${ }^{*} p<0.01$ vs Ca; ${ }^{s} p<0.05$ vs Cr; ${ }^{* \# \#} p<0.001$ vs HF.

rats $(1.87 \pm 0.20)$ than in HF rats $(p<0.04)$. Plasma total ghrelin did not differ significantly between the four groups (Table 5).

\section{PLASMA LEPTIN AND HYPOTHALAMIC LEPTIN RECEPTOR EXPRESSION IN ADULT RATS}

Plasma leptin levels and expression of the long form of the leptin receptor $(\mathrm{Ob}-\mathrm{Rb})$ in the $\mathrm{ARC}$ of the hypothalamus are shown in Figure 5. At the end of the experiment (20 weeks of age), plasma leptin levels were greater in $\mathrm{HC}$ rats than in $\mathrm{Cr}$ and $\mathrm{HF}$ rats $(p<0.001$ for both; Figure $5 \mathrm{~A})$. Ob-Rb mRNA expression was significantly modified by dietary treatment $(p<0.005)$. It was higher in HF $(+86 \% ; p<0.01)$, in Cr rats $(+51 \% ; p<0.05)$, and in $\mathrm{HC}$ rats $(+33 \% ; p<0.05)$ than in Ca rats (Figure 5B). In HF rats, it was also significantly higher than in $\mathrm{HC}$ rats $(p<0.05$; Figure 5B).

Leptin levels were correlated with total fat depot weight and subcutaneous fat depot weight (Figures 6A,B).

Hypothalamic Ob-Rb expression was inversely correlated with contribution of subcutaneous tissue to fat mass and with circulating leptin concentrations (Figures 6C,D).

\section{DISCUSSION}

The prevalence of obesity and metabolic syndrome continues to increase in developed Western societies as well as in developing countries (James, 2004; Diouf et al., 2010; Flegal et al., 2010; Popkin, 2010). This phenomenon is clearly linked to the impact on the human genotype of continuous availability of energy dense and unbalanced diets that lead to epigenetic modifications that increase their susceptibility to develop overweight and diabetes. Since the pioneering work of Barker (Godfrey and Barker, 2000), it appears that the early periods of development (gestation, suckling) are particularly sensitive to these environmental factors. Programming of metabolism is largely completed during these periods and, the imprint of these early changes can have life-long consequences. It is therefore of great importance to define which conditions lead to such deleterious effects.

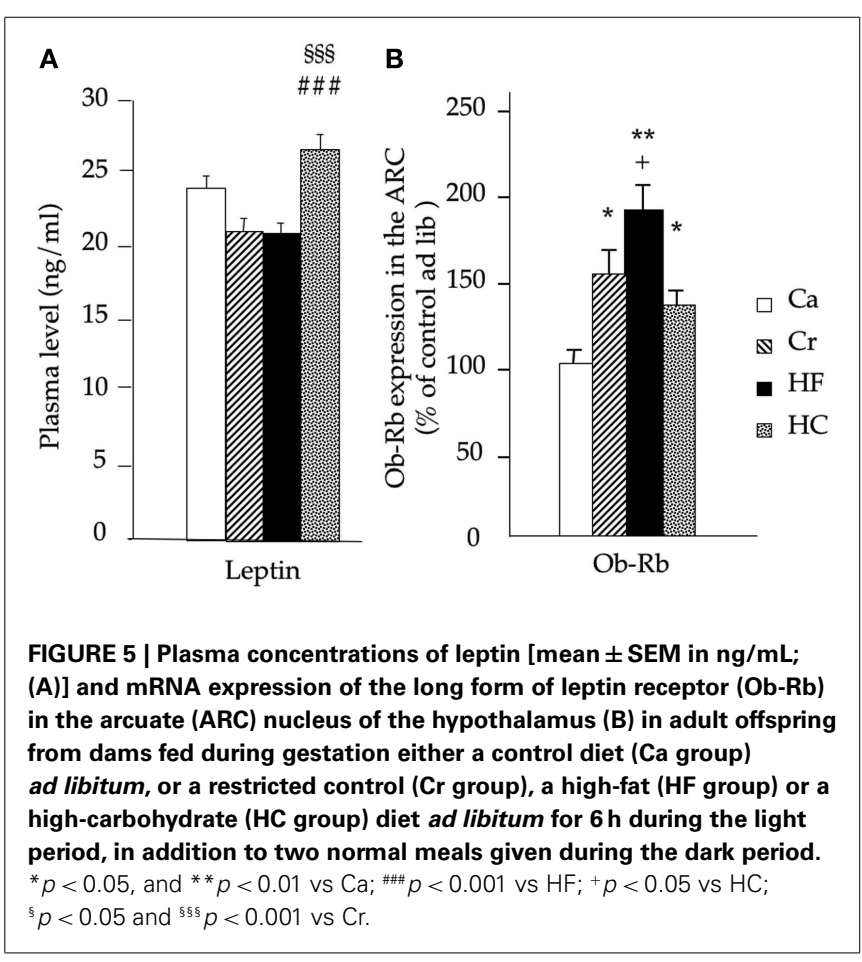

In this experimental animal model, we tried to mimic some of the food consumption patterns observed in pregnant women in order to study the impact of such behaviors and diets on the development of offspring and susceptibility of offspring to metabolic syndrome. To generate a relevant model, we modified the feeding conditions of female rats during the second part gestational days 12 to delivery of gestation. This corresponds to a period of rapid fetal growth and the development of the main regulatory systems, particularly in the brain. To mimic contemporary circumstances as accurately as possible, we fed pregnant females two meals timed to coincide with normal active feeding periods, and 

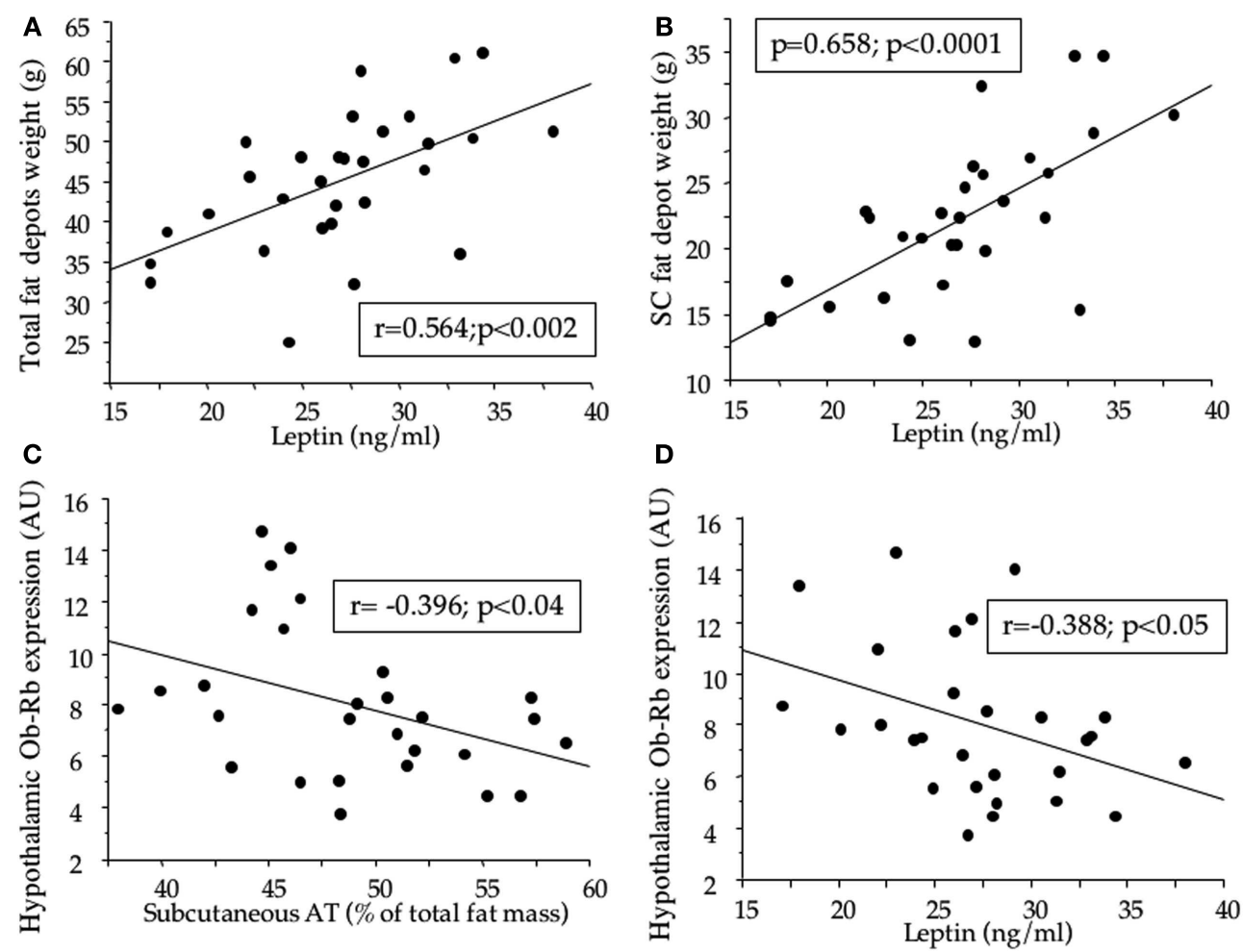

FIGURE 6 | Correlations between fat depot weights and leptin $(A, B)$, fat depot weight and hypothalamic leptin receptor (Ob-Rb) expression (C), and $\mathrm{Ob}-\mathrm{Rb}$ expression and leptin (D) in adult offspring from dams fed during gestation either a control diet

ad libitum, or a control, a high-fat, or a high-carbohydrate diet ad libitum for $\mathbf{6} \mathrm{h}$ during the light period, in addition to two normal meals given during the dark period. $\mathrm{AU}$ : arbitrary unit; $\mathrm{SC}$ : subcutaneous.

corresponding to two-thirds of their pre-gestational $24 \mathrm{~h}$ intake. Rats were then allowed to complete their caloric intake with either a balanced habitual diet, a HF diet or a HC diet available ad libitum for $6 \mathrm{~h}$ during the light period. This $6 \mathrm{~h}$ time interval usually corresponds to a period of less active feeding in the rats and may mimic ingestion of extra-food out of the meal schedule in humans.

Differences were noted between females ingesting the same adequate control diet given ad libitum throughout ( $\mathrm{Ca}$ dams) or during restricted time intervals ( $\mathrm{Cr}$ dams). The $\mathrm{Cr}$ females ingested less calories than the $\mathrm{Ca}$ females. Their intake increased by about $20 \%$ compared with before gestation, but this was about half of the increase recorded in the ad libitum fed females. Accordingly, the Cr pups had a body weight deficit from birth that persisted until at least week 10 of postnatal life. This deficit may be related to the slightly lower food intake recorded for Cr rats until PN week 6.

In the $\mathrm{HC}$ mothers and offspring, similar relative reductions in body weight were observed, although the deficit was not observed beyond 6 weeks of life in the $\mathrm{HC}$ offspring. For these $\mathrm{HC}$ offspring, the data are clearly different from the increased birth weight observed in pups born to dams fed HC diet ad libitum in earlier studies (Koski et al., 1986; Hausman et al., 1991; Kozak et al., 1998). These results confirm the importance of carbohydrate supply for fetal development during the late phase of gestation (Koski and Hill, 1986).

However, the $\mathrm{HC}$ and $\mathrm{Cr}$ groups, although both growth restricted, differed substantially in terms of leptin and insulin

levels. In Cr rats, leptin levels were consistent with their lower body weight (Considine et al., 1996; Beck and Richy, 2008), whereas the $\mathrm{HC}$ offspring were characterized by higher plasma levels of insulin and leptin despite their lower body weight. This suggests the development of both leptin and insulin resistance, a possibility supported by elevated blood glucose in adult HC offspring. Similar hyperinsulinemia has been detected in adult offspring after either imposed moderate calorie (Palou et al., 2010) or protein (Dollet et al., 1987; Fernandez Twinn et al., 2005) restriction during gestation. The divergent results between $\mathrm{Cr}$ and $\mathrm{HC}$ rats indicate that the development of leptin resistance is not an inevitable consequence of low birth weight, contrary to some data obtained in humans (Phillips et al., 1999). Ghrelin has been shown to play a role in the development of glucose intolerance in older animals with increased active ghrelin levels (Reed et al., 2008). Similar ghrelin concentrations found in the two groups in our experiment indicate that insulin resistance was not related to changes in this hormone.

The changes measured in dams allowed to ingest a fat-rich dietary supplement and in their pups are rather different from those found in the other two ( $\mathrm{HC}$ and $\mathrm{Cr}$ ) restricted groups. The HF dams were the only restricted group where energy intake was not decreased. In fact, the HF group ingested more energy than the Ca dams and their intake was about $60 \%$ higher than before gestation. This may reflect the high-energy density of the HF diet $(5.7 \mathrm{kcal} / \mathrm{g})$, that may not be adequately compensated for enhanced 
palatability. Accordingly, body weights of HF offspring did not differ from Ca offspring at any point in the study. These results differ from those obtained from offspring of dams fed a HF diet ad libitum throughout gestation and/or suckling periods in previous studies (Kozak et al., 1998; Wu et al., 1998; Srinivasan et al., 2006; Howie et al., 2009), where higher or lower body weights have been reported depending on the level of dietary fat content. HF and Ca offspring also had similar insulin and leptin concentrations. Thus, they did not present any signs of hormonal resistance or disturbance contrary to what is observed in some (Wu et al., 1998; FerezouViala et al., 2007; Cerf et al., 2009) but not all (Gregersen et al., 2005) studies of the offspring of ad libitum HF fed dams.

A common trait amongst the three restricted groups is the elevated hypothalamic Ob-Rb expression when compared with ad libitum fed control ( $\mathrm{Ca}$ ) rats, an increase that appears directly related to the feeding conditions. Gene expression was quantified in the ARC, a pivotal area involved in feeding and body weight regulation where leptin through its binding to its receptor, can modulate both orexigenic and anorexigenic pathways (Beck, 2005). This increase might be partly explained by caloric restriction in $\mathrm{Cr}$ and $\mathrm{HC}$ rats since a recent study has shown that imposed maternal calorie restriction up-regulates the expression of this long form of leptin receptor (Manuel Apolinar et al., 2010). For the HF offspring, however, a different explanation is required since HF dams overconsume calories during pregnancy. The macronutrient composition of the excess calories ingested, i.e., fat-enriched, may be the primary cause of the increased $\mathrm{Ob}-\mathrm{Rb}$ expression since dietary fat is closely linked to leptin metabolism (Ahren et al., 1997; Stricker-Krongrad et al., 1998). These results agree with those obtained with extended pre-and postnatal exposure of dams to a HF diet (Page et al., 2009), but differ from those obtained immediately after birth (PND 1) where hypothalamic leptin receptor expression was diminished (Morris and Chen, 2009). This discrepancy reveals a deleterious adaptation to solid food after weaning. The relatively lower level of plasma leptin associated with the increased $\mathrm{Ob}-\mathrm{Rb}$ expression might constitute a counterregulatory mechanism to control intake and body weight gain on an energy dense diet (Lin et al., 2000; Page et al., 2009; Shiraev et al., 2009). This interpretation might also be valid for Cr offspring. On the contrary, increased leptin with the smallest increase in Ob$\mathrm{Rb}$ expression in $\mathrm{HC}$ rats could indicate the development of leptin resistance. It is possible that, if the $\mathrm{HC}$ offspring had been placed in a feeding situation with unrestrained high-energy diet after weaning, this situation would have worsened with the rats developing a frank metabolic syndrome. This hypothesis will be examined in our future studies with this model. The data on fat distribution in $\mathrm{HC}$ offspring where subcutaneous adipose tissue is increased, correlate well with their leptin resistance since fasting leptin levels are strongly associated with subcutaneous fat but not with intra-abdominal fat (Cnop et al., 2002), whereas visceral adipose tissue accumulation is more likely associated to insulin resistance or more generally to metabolic syndrome (Despres, 2006).

The observed hormonal variations had little impact on dietary preferences in the different groups of rats in adulthood. All rats had a preference for the sweet (HC) solution. This corresponds to the usual food choice of rats at this life period (Leibowitz et al., 1991; Kozak et al., 2005). Nevertheless, comparison of diet preference in light and dark periods has revealed some interesting differences.
The Cr rats spontaneously ingested more calories than the other three groups in the dark period. This increased intake was mainly, but not exclusively due to an elevated intake of the fat solution. Daily chow intake was not different between $\mathrm{Cr}$ and other groups. The difference in dietary preferences might be important for future weight gain and composition if $\mathrm{Cr}$ rats were provided with a choice between various food sources. A greater intake of fat-rich food would favor fat deposition in adipose tissue and therefore obesity (Warwick and Schiffman, 1992; Beck et al., 1994). Such a situation was not observed in $\mathrm{HC}$ rats despite a similar feeding behavior in terms of energy intake by their mothers. This indicates that $\mathrm{HC}$ diet and control diet may have programmed different feeding mechanisms during gestation.

The new type of dietary manipulation during gestation employed in the current study was originally conceived to resemble some of the preferences and craving for sweet or fatty food exhibited by pregnant women. It combines habitual meal and diet intake with availability and ingestion of unbalanced diets outside of these meal periods. Our data show that these unbalanced supplement intakes do not have a negative impact on either body weight or lipid metabolism in adulthood when a normal balanced diet is ingested from birth. It is also clear that late pregnancy is a sensitive period during which the HC content in the diet and, to a lesser extent, relative calorie restriction can alter programming of different hormonal systems. The extra intake of $\mathrm{HC}$ diet during this period appears to program insulin and leptin resistance in adult offspring and may predispose the development of obesity and associated metabolic disorders if feeding conditions change to palatable energy dense diets. A defective insulin and/or leptin signaling is a primary sign of obesity-prone animals (Huang et al., 2004; Munzberg et al., 2004; Clegg et al., 2005; Irani et al., 2007). The data we obtained with the Cr group highlighted another aspect of feeding behavior of pregnant women, that is, a voluntary diminution of their energy intake to limit (or control) weight gain. A voluntary calorie restriction as seen in the $\mathrm{Cr}$ group could play a subtle role in predisposition to obesity by modifying dietary preferences toward increased fat and calorie intake. This might be linked to programming of hypothalamic pathways as neuropeptides present in the arcuate or paraventricular nucleus are major determinants of food choice (Beck, 2000; Beck et al., 2001). Further experiments are necessary to confirm this hypothesis and the importance of caloric restriction. The main finding of this experiment remains that adult male rat offspring from dams on a $\mathrm{HC}$ diet presented hyperglycemia and hyperinsulinemia that was associated with increased gene expression of the leptin receptor. These changes are indicative of metabolic syndrome. Therefore, the carbohydrate content in the diet should be controlled during the last weeks (or months) preceding delivery to limit development of later metabolic disorders in offspring.

\section{ACKNOWLEDGMENTS}

The authors wish to thank Ms. Françoise Bergerot, Mr. Antoine Fillion, Mr. Francesco Giannangelli and Mr. Thierry Anthony for their excellent technical help and animal care. The authors have no conflict of interest to disclose. This study was supported by the European Commission, Quality of Life and Management of Living Resources, Key action 1 "Food, nutrition and health" programme (QLK1-2000-00515). 


\section{REFERENCES}

Ahren, B., Mansson, S., Gingerich, R. L., and Havel, P. J. (1997). Regulation of plasma leptin in mice: influence of age, high-fat diet, and fasting. Am. J. Physiol. 42, R113-R120.

Bayol, S. A., Farrington, S. J., and Stickland, N. C. (2007). A maternal "junk food" diet in pregnancy and lactation promotes an exacerbated taste for "junk food" and a greater propensity for obesity in rat offspring. Br. J. Nutr. 98, 843-851.

Beck, B. (2000). "Quantitative and macronutrient-related regulation of hypothalamic neuropeptide $\mathrm{Y}$, galanin and neurotensin," in Neural and Metabolic Control of Macronutrient Intake, eds H. R. Berthoud and R. J. Seeley (Boca Raton, FL: CRC Press), 455-464.

Beck, B. (2005). "The arcuate nucleus: its special place in the central networks that regulate feeding behavior," in Nutrient and Cell Signalling, ed. J. D. K. Zempleni (New-York: Dekker), 665-699.

Beck, B., and Richy, S. (2008). Differential long-term dietary regulation of adipokines, ghrelin, or corticosterone: impact on adiposity. $J$. Endocrinol. 196, 171-179.

Beck, B., Stricker-Krongrad, A., Burlet, A., Cumin, F., and Burlet, C. (2001). Plasma leptin and hypothalamic neuropeptide $\mathrm{Y}$ and galanin levels in Long-Evans rats with marked dietary preferences. Nutr. Neurosci. 4, 39-50.

Beck, B., Stricker-Krongrad, A., Burlet, A., Max, J. P., Musse, N., Nicolas, J. P., and Burlet, C. (1994). Macronutrient type independently of energy intake modulates hypothalamic neuropeptide $\mathrm{Y}$ in LongEvans rats. Brain Res. Bull. 34, 85-91.

Bispham, J., Gopalakrishnan, G. S., Dandrea, J., Wilson, V., Budge, H., Keisler, D. H., Broughton Pipkin, F., Stephenson, T., and Symonds, M. E. (2003). Maternal endocrine adaptation throughout pregnancy to nutritional manipulation: consequences for maternal plasma leptin and cortisol and the programming of fetal adipose tissue development. Endocrinology 144, 3575-3585.

Bowen, D. J. (1992). Taste and food preference changes across the course of pregnancy. Appetite 19, 233-242.

Brion, M. J. A., Ness, A. R., Rogers, I., Emmett, P., Cribb, V., Smith, G. D., and Lawlor, D. A. (2010). Maternal macronutrient and energy intakes in pregnancy and offspring intake at 10 $\mathrm{y}$ : exploring parental comparisons and prenatal effects. Am. J. Clin. Nutr. 91, 748-756.
Buckley, A. J., Keseru, B., Briody, J., Thompson, M., Ozanne, S. E., and Thompson, C. H. (2005). Altered body composition and metabolism in the male offspring of high fat-fed rats. Metab. Clin. Exp. 54, 500-507.

Butte, N. F., Hopkinson, J. M., Mehta, N., Moon, J. K., and Smith, E. O. (1999). Adjustments in energy expenditure and substrate utilization during late pregnancy and lactation. Am. J. Clin. Nutr. 69, 299-307.

Butte, N. F., Wong, W. W., Treuth, M. S., Ellis, K. J., and Smith, E. O. (2004). Energy requirements during pregnancy based on total energy expenditure and energy deposition. Am. J. Clin. Nutr. 79, 1078-1087.

Cerf, M. E., Chapman, C. S., Muller, C. J., and Louw, J. (2009). Gestational high-fat programming impairs insulin release and reduces $\mathrm{Pdx}-1$ and glucokinase immunoreactivity in neonatal Wistar rats. Metab. Clin. Exp. 58, 1787-1792.

Chang, G. Q., Gaysinskaya, V., Karatayev, O., and Leibowitz, S. F. (2008). Maternal high-fat diet and fetal programming: increased proliferation of hypothalamic peptide-producing neurons that increase risk for overeating and obesity. J. Neurosci. 28, 12107-12119.

Clegg, D. J., Benoit, S. C., Reed, J. A., Woods, S. C., DunnMeynell, A., and Levin, B. E. (2005). Reduced anorexic effects of insulin in obesityprone rats fed a moderate-fat diet. Am. J. Physiol. 288, R981-R986.

Cnop, M., Landchild, M. J., Vidal, J., Havel, P. J., Knowles, N. G., Carr, D. R., Wang, F., Hall, R. L., Boyko, E. J., Retzlaff, B. M., Walden, C. E., Knopp, R. H., and Kahn, S. E. (2002). The concurrent accumulation of intra-abdominal and subcutaneous fat explains the association between insulin resistance and plasma leptin concentrations - distinct metabolic effects of two fat compartments. Diabetes 51, 1005-1015.

Considine, R. V., Sinha, M. K., Heiman, M. L., Kriauciunas, A., Stephens, T. W., Nyce, M. R., Ohannesian, J. P., Marco, C. C., Mckee, L. J., Bauer, T. L., and Caro, J. F. (1996). Serum immunoreactive leptin concentrations in normal-weight and obese humans. N. Engl. J. Med. 334, 292-295.

Cottrell, E. C., and Ozanne, S. E. (2008). Early life programming of obesity and metabolic disease. Physiol. Behav. 94, 17-28.

Despres, J. P. (2006). Is visceral obesity the cause of the metabolic syndrome? Ann. Med. 38, 52-63.
Dickens, G., and Trethowan, W. H. (1971). Cravings and aversions during pregnancy. J. Psychosom. Res. 15, 259-268.

Diouf, I., Charles, M. A., Ducimetiere, P., Basdevant, A., Eschwege, E., and Heude, B. (2010). Evolution of obesity prevalence in France. An ageperiod-cohort analysis. Epidemiology 21, 360-365.

Dollet, J. M., Beck, B., Max, J. P. and Debry, G. (1987). Proteinenergy malnutrition in pregnant rats improves adaptation of endocrine pancreas in malnourished offspring and induces insulin resistance after rehabilitation. Br. J. Nutr. 58, 415-425.

Dyrskog, S. E., Gregersen, S., and Hermansen, K. (2005). High-fat feeding during gestation and nursing period have differential effects on the insulin secretory capacity in offspring from normal Wistar rats. Rev. Diabet. Stud. 2, 136-145.

FerezouViala, J., Roy, A. F., Serougne, C., Gripois, D., Parquet, M., Bailleux, V., Gertler, A., Delplanque, B., Djiane, J., Riottot, M., and Taouis, M. (2007). Long-term consequences of maternal high-fat feeding on hypothalamic leptin sensitivity and dietinduced obesity in the offspring. Am. J. Physiol. 293, R1056-R1062.

Fernandez Twinn, D. S., Wayman, A., Ekizoglou, S., Martin, M. S., Hales, C. N., and Ozanne, S. E. (2005). Maternal protein restriction leads to hyperinsulinemia and reduced insulin-signaling protein expression in 21-mo-old female rat offspring. Am. J. Physiol. 288, R368-R373.

Flegal, K. M., Carroll, M. D., Ogden, C. L., and Curtin, L. R. (2010). Prevalence and trends in obesity among US adults, 1999-2008. JAMA 303, 235-241.

Godfrey, K. M., and Barker, D. J. P. (2000). Fetal nutrition and adult disease. Am. J. Clin. Nutr. 71, 1344S$1352 \mathrm{~S}$.

Gregersen, S., Dyrskog, S. E. U., Storlien, L. H., and Hermansen, K. (2005). Comparison of a high saturated fat diet with a high carbohydrate diet during pregnancy and lactation: effects on insulin sensitivity in offspring of rats. Metab. Clin. Exp. 54, 1316-1322.

Hausman, D. B., Mc Closkey, H. M., and Martin, R. J. (1991). Maternal fat type influences the growth and fatty acid composition of newborn and weanling rats. J. Nutr. 121, 1917-1923.

Hook, E. B. (1978). Dietary cravings and aversions during pregnancy. Am. J. Clin. Nutr. 31, 1355-1362.
Howie, G. J., Sloboda, D. M., Kamal, T., and Vickers, M. H. (2009). Maternal nutritional history predicts obesity in adult offspring independent of postnatal diet. J. Physiol. (Lond.) 587, 905-915.

Huang, X. F., Xin, X., McLennan, P., and Storlien, L. (2004). Role of fat amount and type in ameliorating diet-induced obesity: insights at the level of hypothalamic arcuate nucleus leptin receptor, neuropeptide $\mathrm{Y}$ and pro-opiomelanocortin mRNA expression. Diabetes Obes. Metab. 6, 35-44.

Irani, B. G., DunnMeynell, A. A., and Levin, B. E. (2007). Altered hypothalamic leptin, insulin, and melanocortin binding associated with moderate-fat diet and predisposition to obesity. Endocrinology $148,310-316$.

James, P. (2004). Obesity: the worldwide epidemic. Clin. Dermatol. 22, 276-280.

Koski, K. G., and Hill, F. W. (1986). Effect of low carbohydrate diets during pregnancy on parturition and postnatal survival of the newborn rat pup. J. Nutr. 116, 1938-1948.

Koski, K. G., Hill, F. W., and Hurley, L. S. (1986). Effect of low carbohydrate diets during pregnancy on embryogenesis and fetal growth and development in rats. J. Nutr. 116, 1922-1937.

Kozak, R., Burlet, A., Burlet, C., and Beck, B. (2000). Dietary composition during fetal and neonatal life affects neuropeptide $\mathrm{Y}$ functioning in adult offspring. Brain Res. Dev. Brain Res. 125, 75-82.

Kozak, R., Mercer, J. G., Burlet, A., Moar, K. M., Burlet, C., and Beck, B. (1998). Hypothalamic neuropeptide Y content and mRNA expression in weanling rats subjected to dietary manipulations during fetal and neonatal life. Regul. Pept. 75, 397-402.

Kozak, R., Richy, S., and Beck, B. (2005). Persistent alterations in neuropeptide $\mathrm{Y}$ release in the paraventricular nucleus of rats subjected to dietary manipulation during early life. Eur. J. Neurosci. 21, 2887-2892.

Leibowitz, S. F., Lucas, D. J., Leibowitz, K. L., and Jhanwar, Y. S. (1991). Developmental patterns of macronutrient intake in female and male rats from weaning to maturity. Physiol. Behav. 50, 1167-1174.

Leturque, A., Ferre, P., Satabin, P., Kervran, A., and Girard, J. (1980). In vivo insulin resistance during pregnancy in the rat. Diabetologia 19, 521-528.

Lin, S., Storlien, L. H., and Huang, X. F. (2000). Leptin receptor, NPY, 
POMC mRNA expression in the diet-induced obese mouse brain. Brain Res. 875, 89-95.

Manuel Apolinar, L., Zarate, A., Rocha, L., and Hernandez, M. (2010). Fetal malnutrition affects hypothalamic leptin receptor expression after birth in male mice. Arch. Med. Res. 41, 240-245.

Marlin, N. A. (1983). Early exposure to sugars influences the sugar preference of the adult rat. Physiol. Behav. 31, 619-623.

Mercer, J. G., Hoggard, N., Williams, L. M., Lawrence, C. B., Hannah, L. T., and Trayhurn, P. (1996). Localization of leptin receptor mRNA and the long form splice variant (ob-rb) in mouse hypothalamus and adjacent brain regions by in situ hybridization. FEBS Lett. 387, 113-116.

Morris, M. J., and Chen, H. (2009). Established maternal obesity in the rat reprograms hypothalamic appetite regulators and leptin signaling at birth. Int. J. Obes. 33, 115-122.

Moses, R. G., Shand, J. L., and Tapsell, L. C. (1997). The recurrence of gestational diabetes: could dietary differences in fat intake be an explanation? Diabetes Care 20, 1647-1650.

Munzberg, H., Flier, J. S., and Bjorbaek, C. (2004). Region-specific leptin resistance within the hypothalamus of diet-induced obese mice. Endocrinology 145, 4880-4889.

Nakashima, Y. (2008). Fish-oil highfat diet intake of dams after day 5 of pregnancy and during lactation guards against excessive fat consumption of their weaning pups. $J$. Nutr. Sci. Vitaminol. 54, 46-53.

Page, K. C., Malik, R. E., Ripple, J. A., and Anday, E. K. (2009). Maternal and postweaning diet interaction alters hypothalamic gene expression and modulates response to a high-fat diet in male offspring. Am. J. Physiol. 297, R1049-R1057.

Palou, M., Priego, T., Sanchez, J., Palou, A., and Pico, C. (2010). Sexual dimorphism in the lasting effects of moderate caloric restriction during gestation on energy homeostasis in rats is related with fetal programming of insulin and leptin resistance. Nutr. Metab. (Lond.) 7, 69 .

Phillips, D. I. W., Fall, C. H. D., Cooper, C., Norman, R. J., Robinson, J. S., and Owens, P. C. (1999). Size at birth and plasma leptin concentrations in adult life. Int. J. Obes. 23, 1025-1029.

Pope, J. F., Skinner, J. D., and Carruth, B. R. (1992). Cravings and aversions of pregnant adolescents. J. Am. Diet. Assoc. 92, 1479-1482.
Popkin, B. M. (2010). Recent dynamics suggest selected countries catching up to US obesity. Am. J. Clin. Nutr. 91, 284S-288S.

Reed, J. A., Benoit, S. C., Pfluger, P. T. Tschoep, M. H., DAlessio, D. A., and Seeley, R. J. (2008). Mice with chronically increased circulating ghrelin develop age-related glucose intolerance. Am. J. Physiol. 294, E752-E760.

Shiraev, T., Chen, H., and Morris, M. J. (2009). Differential effects of restricted versus unlimited highfat feeding in rats on fat mass, plasma hormones and brain appetite regulators. J. Neuroendocrinol. 21, 602-609.

Srinivasan, M., Katewa, S. D., Palaniyappan, A., Pandya, J. D., and Patel, M. S. (2006). Maternal high-fat diet consumption results in fetal malprogramming predisposing to the onset of metabolic syndrome-like phenotype in adulthood. Am. J. Physiol. 291, E792-E799.

Stricker-Krongrad, A., Cumin, F., Burlet, C., and Beck, B. (1998). Hypothalamic neuropeptide $\mathrm{Y}$ and plasma leptin after long-term high-fat feeding in the rat. Neurosci. Lett. 254 157-160.

Warwick, Z. S., and Schiffman, S. S. (1992). Role of dietary fat in calorie intake and weight gain. Neurosci. Biobehav. Rev. 16, 585-596.
Wu, Q., Mizushima, Y., Komiya, M. Matsuo, T., and Suzuki, M. (1998). Body fat accumulation in the male offspring of rats fed highfat diet. J. Clin. Biochem. Nutr. 25, 71-79.

Conflict of Interest Statement: The authors declare that the research was conducted in the absence of any commercial or financial relationships that could be construed as a potential conflict of interest.

Received: 28 March 2012; accepted: 04 June 2012; published online: 25 June 2012.

Citation: Beck B, Richy S, Archer ZA and Mercer JG (2012) Ingestion of carbohydrate-rich supplements during gestation programs insulin and leptin resistance but not body weight gain in adult rat offspring. Front. Physio. 3:224. doi: 10.3389/fphys.2012.00224

This article was submitted to Frontiers in Integrative Physiology, a specialty of Frontiers in Physiology.

Copyright (C) 2012 Beck, Richy, Archer and Mercer. This is an open-access article distributed under the terms of the Creative Commons Attribution Non Commercial License, which permits noncommercial use, distribution, and reproduction in other forums, provided the original authors and source are credited. 